\title{
Regime-based analysis of aerosol-cloud interactions
}

\author{
Edward Gryspeerdt ${ }^{1}$ and Philip Stier ${ }^{1}$ \\ Received 27 July 2012; revised 24 September 2012; accepted 29 September 2012; published 1 November 2012.
}

[1] Previous global satellite studies into the indirect aerosol effect have relied on determining the sensitivity of derived Cloud Droplet Number Concentration $\left(\mathrm{N}_{\mathrm{d}}\right)$ to co-located Aerosol Optical Depth (AOD). These studies generally find a positive $\mathrm{N}_{\mathrm{d}}$ sensitivity to AOD changes over ocean, but some find a negative sensitivity over land, in contrast to that predicted by models and theory. Here we investigate the $\mathrm{N}_{\mathrm{d}}$ sensitivity to AOD in different cloud regimes, determined using a k-means clustering process on retrieved cloud properties. We find the strongest positive $\mathrm{N}_{\mathrm{d}}$ sensitivity in the stratiform regimes over both land and ocean, providing the majority of the total sensitivity. The negative sensitivity previously observed over land is generated by the low cloud fraction regimes, suggesting that it is due to the difficulty of retrieving $\mathrm{N}_{\mathrm{d}}$ at low cloud fractions. When considering a mean sensitivity, weighted by liquid cloud fraction to account for sampling biases, we find an increased sensitivity over land, in some regions becoming positive. This highlights the importance of regime based analysis when studying aerosol indirect effects. Citation: Gryspeerdt, E., and P. Stier (2012), Regime-based analysis of aerosol-cloud interactions, Geophys. Res. Lett., 39, L21802, doi:10.1029/2012GL053221.

\section{Introduction}

[2] Aerosols are thought to have a large effect on the climate, both through the direct effect on radiation, and through their interaction with clouds. The magnitude of these effects, especially aerosol-cloud interactions, are very uncertain, with the radiative forcing from aerosol induced changes in cloud albedo reported as $-0.8 \mathrm{Wm}^{-2}$, but with an uncertainty range of -0.3 to $-1.5 \mathrm{Wm}^{-2}$ [Forster et al., 2007]. This effect is large enough that it could offset much of the warming from greenhouse gases [e.g., Huber and Knutti, 2011], emphasizing the need to understand the effect so that we can better predict the future climate.

[3] Several different indirect effects have been theorized, with increases in cloud albedo [Twomey, 1977], cloud fraction (CF) [Albrecht, 1989] and decreases of cloud top pressure (CTP) [Koren et al., 2005] in regions of increased aerosol. In this study we concentrate on the cloud-albedo effect, the change in cloud albedo with increasing aerosol. Given that cloud droplets form on aerosol particles, an increase in aerosol particles at constant cloud water content is thought to decrease droplet size [Gunn and Phillips,

\footnotetext{
${ }^{1}$ Department of Physics, University of Oxford, Oxford, UK.

Corresponding author: E. Gryspeerdt, Department of Physics, University of Oxford, Parks Road, Oxford OX1 3PU, UK.

(C)2012. American Geophysical Union. All Rights Reserved. 0094-8276/12/2012GL053221
}

1957], which in turn increases the brightness of the cloud due to the increased scattering of the smaller, more numerous cloud droplets.

[4] Satellite studies on the cloud albedo effect have concentrated on the sensitivity of Cloud Droplet Effective Radius $\left(\mathrm{r}_{e}\right)$ and Cloud Droplet Number Concentration $\left(\mathrm{N}_{\mathrm{d}}\right)$ to Aerosol Optical Depth (AOD). Kaufman et al. [2005] found a decrease in $r_{e}$ in shallow clouds over the Atlantic ocean with increasing AOD. A corresponding increase in $\mathrm{N}_{\mathrm{d}}$ with increasing AOD was found by Quaas et al. [2008], who used the CERES science team retrieval of data from the MODIS (Moderate resolution Imaging Spectrometer) instrument over large regions to determine the correlation between $\mathrm{N}_{\mathrm{d}}$ and AOD. Such satellite correlations are based on the assumption that AOD is a suitable proxy for Cloud Condensation Nuclei (CCN) [Andreae, 2009].

[5] These studies confine their data to specific regions for the purposes of determining the sensitivity of cloud properties to AOD based on the assumption that the aerosol and cloud properties are largely similar across each region. However, Grandey and Stier [2010] showed that this assumption is not valid over regions larger than about $4^{\circ} \times 4^{\circ}$, due to the possibility of climatological spatial gradients of the aerosol and cloud properties across the region generating spurious correlations. They also note that the sensitivity of $\mathrm{N}_{d}$ to AOD is negative over land when using MODIS collection 5 data, which would result in a positive indirect radiative forcing from the cloud albedo effect over land, in contrast to model results [Quaas et al., 2009].

[6] Whilst these, and other studies based on the CERES retrieval take into account spatial variations of cloud properties, they do not consider how different cloud types vary in their responses to AOD changes. Stratifying by pressure vertical velocity has previously been used to separate out different cloud regimes [Bony et al., 2004], with stratocumulus clouds being much more likely to form in regions of positive pressure vertical velocity. Jones et al. [2009] consider the indirect effect using data stratified by $850 \mathrm{hPa}$ pressure vertical velocity but find very little change in the indirect forcing between regions of ascending and descending air. However, these large scale properties may not be suitable for determining cloud regimes locally. Rossow et al. [2005] suggest that satellite cloud properties provide a better description of the local state of the atmosphere.

[7] In this study we use cloud and aerosol data from the MODIS instrument to study the sensitivity of $N_{d}$ to AOD perturbations. By using the objective clustering method of Williams and Webb [2009] to determine tropical cloud regimes, we calculate this sensitivity for different liquid cloud regimes to determine which regimes are most important to the indirect forcing and ultimately bring this type of statistical satellite approach closer to the physically relevant process scale. In addition, this regime based method also 
Table 1. Properties of the Regime Centroids Used in This Study ${ }^{\mathrm{a}}$

\begin{tabular}{lccccc}
\hline \multicolumn{1}{c}{ Regime } & Albedo & $\begin{array}{c}\text { CTP } \\
\text { (hPa) }\end{array}$ & $\begin{array}{c}\text { CF } \\
(\%)\end{array}$ & $\begin{array}{c}\text { RFO } \\
(\%)\end{array}$ & $\begin{array}{c}\text { Sens } \\
(\%)\end{array}$ \\
\hline Transition & 0.405 & 856 & 58.3 & 14.3 & 18 \\
Deep Convection & 0.697 & 127 & 98.6 & 3.7 & -2 \\
Stratocumulus & 0.487 & 745 & 83.9 & 9.4 & 58 \\
Anvil Cirrus & 0.337 & 137 & 88.0 & 4.5 & 0 \\
Thick Mid. Level & 0.628 & 261 & 97.6 & 9.5 & 11 \\
Thin Mid. Level & 0.400 & 270 & 84.3 & 8.6 & 7 \\
Shallow Cumulus & 0.452 & 551 & 24.7 & 50.0 & 11 \\
\hline
\end{tabular}

${ }^{a}$ Included are regime relative frequency of occurrence (RFO) and the contribution to the total mean sensitivity (Sens).

investigates the contribution made by sampling biases to the observed relationships.

\section{Methods}

[8] We separate the clouds into different regimes using the method of Williams and Webb [2009]. This method uses a kmeans clustering process [Anderberg, 1973] on the MODIS Cloud Top Pressure-Cloud Optical Depth (CTP-COD) collection 5.1 daily level 3 histogram at $1^{\circ} \times 1^{\circ}$ resolution. The k-means clustering algorithm requires the number of clusters as an input, which we determine following the method of Rossow et al. [2005]. Starting at four clusters, the number of clusters is increased and the clusters are judged by whether they fulfill the following conditions: 1) The cluster centroid histograms do not change significantly when the clustering process is re-run with different starting centroids; 2) The resulting cluster centroid patterns should differ from each other such that the correlations between them are low (usually $<0.6$ ); 3) The spatial and temporal correlations between the frequency of occurrence patterns of the regimes should be low. Strong correlations between the centroid histograms or the frequency of occurrence patterns may indicate that a cluster is being repeated. In a similar fashion to Williams and Webb [2009], we also impose the additional condition that the total relative frequency of occurrence (RFO) of each of the regimes should be above $3.5 \%$, as these low frequency clusters tend to be sensitive to the initial seeding of the clusters. We use the largest number of clusters which satisfies these criteria.

[9] We find seven clusters in the tropics $\left(30^{\circ} \mathrm{N}-30^{\circ} \mathrm{S}\right)$ (Table 1) when using 1 year of MODIS Aqua data. When dealing with the full set of data from 2003-2011, each level 3 pixel is assigned to the regime with the closest mean properties (CF, CTP and albedo). This assignment method improves the speed of the assignment while having a negligible effect on the regime histograms. Figure 1 shows the relative frequencies of occurrence of the different regimes. The transition regime refers to the transition between the shallow cumulus and the stratocumulus regimes.

[10] We use MODIS Aqua collection 5.1 level 3 daily data at $1^{\circ} \times 1^{\circ}$ resolution for our aerosol [Remer et al., 2005] and cloud [Platnick et al., 2003] property retrievals, with Optical_Depth_Land_And_Ocean_Mean as our AOD product. To estimate $\mathrm{N}_{\mathrm{d}}$, we use the adiabatic approximation (Equation 1) [Brenguier et al., 2000], where $\tau_{c}$ is the cloud optical depth, and $\gamma=1.37 \times 10^{-5} \mathrm{~m}^{-\frac{1}{2}}$ [Quaas et al., 2006].

$$
N_{d}=\gamma \tau_{c}^{\frac{1}{2}} r_{e}^{-\frac{5}{2}}
$$

[11] This relationship assumes that the liquid water content and droplet radius increase monotonically in the cloud, and that $r_{e}$ is representative of the true droplet radius at the top of the cloud. Non-precipitating marine stratocumulus clouds have been observed to be approximately adiabatic [e.g., Zuidema et al., 2005], but continental clouds can show significant departures from adiabaticity [Kim et al., 2005]. Following Grandey and Stier [2010], we have calculated $\mathrm{N}_{\mathrm{d}}$ using the $\tau_{\mathrm{c}}-\mathrm{r}_{\mathrm{e}}$ joint histogram in the MODIS level 3 product, excluding bins where $\tau_{\mathrm{c}}<4$ and $\mathrm{r}_{\mathrm{e}}<4$. We use the joint histogram for liquid clouds when calculating $\mathrm{N}_{\mathrm{d}}$, limiting our results to only the liquid clouds.


Thick Mid Level



Shallow Cumulus







Relative frequency of occurence



Cloud amount (histograms)






Cloud Optical Depth

Figure 1. Maps of the relative frequency of occurrence (RFO) and joint Cloud Top Pressure-Cloud Optical Depth histograms of each cloud regime between $30^{\circ} \mathrm{N}$ and $30^{\circ} \mathrm{S}$. Note that the histogram color bar has been slightly re-scaled compared to Williams and Webb [2009] to better display low cloud amount bins. 



g) Thin Mid Level


Sensitivity



Figure 2. Sensitivity of cloud droplet effective number concentration $\left(\mathrm{N}_{\mathrm{d}}\right)$ to aerosol optical depth (AOD) for the separate regimes. This uses 9 years of Aqua-MODIS collection 5.1 cloud and aerosol products, from 2003-2011. Only relationships significant at the 2-sigma level are shown.

[12] To calculate the sensitivities, we follow the method of Feingold et al. [2003], where the sensitivity $\left(\mathrm{b}_{\mathrm{N}_{\mathrm{d}}}\right)$, of $\mathrm{N}_{\mathrm{d}}$, to AOD is given by

$$
b_{\mathrm{N}_{\mathrm{d}}}=\frac{\mathrm{d} \ln \mathrm{N}_{\mathrm{d}}}{\mathrm{d} \ln \mathrm{AOD}} .
$$

[13] We calculate the sensitivities separately for each season DJF, MAM, JJA and SON, and ignore pixels with fewer than five retrievals before calculating the one-sigma error-weighted mean.

\section{Results}

[14] When considering all the data for determining the sensitivity of droplet effective number concentration to AOD (Figure $2 \mathrm{~h}$ ), we find a strong positive sensitivity over ocean, indicating that an increase in AOD is correlated with an increased $\mathrm{N}_{\mathrm{d}}$. Over land, we find a predominantly negative relationship, which is not seen either in climate models, or when using cloud data from the CERES science team retrieval of cloud properties from MODIS [Quaas et al., 2009]. This negative sensitivity is not consistent with conventional theories of the cloud albedo effect which predict an increase in cloud albedo with increasing CCN. The pattern of negative sensitivities observed is not consistent with semi-direct effects expected to occur in regions with significant aerosol absorption [e.g., Stier et al., 2007], as they would not be expected to show such a clear land-sea contrast. It is possible that differing applicability of the adiabatic assumption in different regimes or an aerosol composition effect such as Yuan et al. [2008], contribute to the observed negative sensitivity. However, the difference in sensitivities found using the different cloud retrievals does point towards errors in the cloud retrieval over land at low cloud fraction being an important cause.

[15] Yuan et al. [2008] find a relationship between cloud droplet radius and AOD which would produce a similar negative sensitivity over land. They determine that this relationship is not primarily due to $3 \mathrm{D}$ effects on the cloud retrieval, perhaps suggesting that the negative sensitivity may be due to the different cloud masks used by the MODIS and CERES science teams.

[16] As expected, the regimes dominated by mixed-phase clouds (deep convective and anvil cirrus) show no significant sensitivity of $\mathrm{N}_{\mathrm{d}}$ to AOD (Figure 2). The regimes with high proportions of liquid clouds (shallow cumulus, transition and stratocumulus) show a positive sensitivity over ocean, indicating that a higher AOD is correlated with a higher $\mathrm{N}_{\mathrm{d}}$. We also see negative sensitivities over land in the shallow cumulus regime, which has a very similar sensitivity pattern to that found when considering all data, due to the high regime RFO. In regions where the correlation is significant at the 2-sigma level, both stratiform regimes show a larger sensitivity than the shallow cumulus regime. The stratocumulus regime shows a strong positive sensitivity over ocean, especially along the western edge of the Pacific, but also over land, in contrast to the negative relationship observed in the shallow cumulus regime.

[17] Failure to consider regimes when calculating sensitivities leads to an under-representation of the high $\mathrm{CF}$ regimes, as aerosol and cloud cannot be retrieved at the same location (about $60 \%$ of stratocumulus regime has no valid AOD retrieval, compared to only $30 \%$ of the shallow cumulus regime). This is especially important given that these regimes have a high proportion of the total liquid cloud amount. To account for this, when we recombine our regime sensitivities to estimate total mean sensitivity, the regime sensitivities are weighted by the total regime RFO, which has no requirement for valid AOD retrievals. This assumes that the regimes behave similarly whether or not there is a co-located AOD retrieval. We also weight by the regime mean liquid $\mathrm{CF}$ in each gridbox, on the basis that the indirect forcing from a regime/gridbox would scale with liquid CF.

[18] In Figure 3 we see that the regime based method (Figure $3 b$ ) is similar to the sensitivity plot without separating and weighting the regimes (Figure $3 \mathrm{a}$ ), but with some notable differences. The sensitivity over ocean decreases slightly, although there are increases in some regions, notably in the Western Pacific, on the edge of the stratocumulus region. In general, the sensitivity increases over land, becoming positive in some regions, compared to a negative sensitivity when regimes are not used. This is in better agreement with models and theory. Given that only the shallow cumulus regime experiences a negative sensitivity over land, this suggests that the negative sensitivity over land may be due to difficulty in retrieving $\mathrm{N}_{\mathrm{d}}$ in low cloud fraction pixels [Bennartz, 2007]. However, here we show that the low CF pixels provide a relatively small contribution to the weighted total sensitivity (Table 1) even though they have a high frequency of occurrence, limiting the impact of this negative sensitivity. The majority of the total sensitivity comes from the stratocumulus regime, due to its high liquid CF compensating for its low frequency of occurrence.

[19] It is also possible that the increase in sensitivity in the higher cloud fractions regimes is not a physical effect, 




b) Regimes weighted by RFO and CF



c)

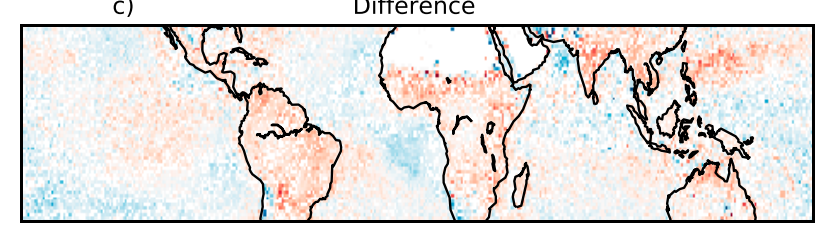

Sensitivity



Figure 3. Comparison between the sensitivity of $\mathrm{N}_{\mathrm{d}}$ to AOD (a) without splitting the data into cloud regimes using a liquid cloud fraction, (b) frequency of occurrence weighted mean, and (c) the difference between the methods. Only relationships significant at the 2-sigma level are shown.

but may be due to one of the numerous different effects which result in the strong relationship between $\mathrm{CF}$ and $\mathrm{AOD}$ [Quaas et al., 2010]. However, the ability to pinpoint the source of the negative sensitivity over land to the low CF retrievals illustrates the importance of regime based analysis.

\section{Conclusion}

[20] In this letter we highlight the importance of regimebased studies of aerosol-cloud interactions, due to the differing interaction strengths of the different regimes.

[21] Using a k-means clustering process on retrieved cloud properties, we have separated nine years of MODIS Aqua data into seven tropical cloud regimes. We have established that the different regimes have differing sensitivities of cloud droplet number concentration $\left(\mathrm{N}_{\mathrm{d}}\right)$ to perturbations in aerosol optical depth (AOD), with the stratiform regimes having the largest sensitivities. The shallow cumulus regime has very similar sensitivity to the total sensitivity determined without using regimes, due to its high relative frequency of occurrence.

[22] Without accounting for the different cloud regimes we find a negative sensitivity over land, in the location of the strongest anthropogenic aerosol perturbations. This negative sensitivity is produced by the low CF shallow cumulus regime and although this could be an aerosol effect, it does not agree with other satellite products, suggesting that it may be due to the difficulty of retrieving $\mathrm{N}_{\mathrm{d}}$ in low CF scenes.

[23] To determine the sensitivity, we require both AOD and cloud property retrievals at the same location. This requirement means that the high cloud fraction (CF) stratiform regimes are typically under-represented in sensitivity determinations due to a lower number of AOD retrievals reducing the apparent regime frequency of occurrence. To compensate for this sampling bias, we use the total regime frequency of occurrence, which is not dependent on AOD retrievals, to determine the regime frequency. In addition, we also weight each regime by its mean liquid $\mathrm{CF}$ to account for the extra contribution high CF regimes make to the forcing.

[24] With these weightings, the stratocumulus regime contributes the most to the total sensitivity ( $58 \%$ of the total) despite its low frequency of occurrence, due to high liquid $\mathrm{CF}$ and regime sensitivity. Due to a low liquid CF, the shallow cumulus regime only makes a small contribution to the total sensitivity ( $11 \%$ of the total), limiting the impact of the negative relationship of this regime. This weighting increases the total sensitivity of $\mathrm{N}_{\mathrm{d}}$ to AOD over land, in some regions changing the sign of the sensitivity to positive, putting it in better agreement with other studies.

[25] This increased sensitivity of $N_{d}$ to AOD over land is particularly significant given that the short lifetime of many aerosol species leads them to be concentrated near sources, which are often over land. This increased sensitivity and the differing sensitivity of the regimes highlights the importance of regime based analysis for investigating the magnitude of the cloud albedo effect.

[26] Acknowledgments. The MODIS data used in this work were obtained from the Goddard Space Flight Center. Edward Gryspeerdt was supported by a UK Natural Environment Research Council (NERC) studentship. The research leading to this work has received funding from the European Research Council under the European Union's Seventh Framework Programme (FP7/2007-2013) / ERC grant agreement FP7-280025. The authors would like to thank Benjamin Grandey, Rosalind West and Nick Schutgens for their valuable comments on the manuscript.

[27] The Editor thanks Jonathan Jiang and an anonymous reviewer for assistance evaluating this paper.

\section{References}

Albrecht, B. (1989), Aerosols, cloud microphysics, and fractional cloudiness, Science, 245, 1227-1230.

Anderberg, M. (1973), Cluster Analysis for Applications, 359 pp., Elsevier, New York.

Andreae, M. (2009), Correlation between cloud condensation nuclei concentration and aerosol optical thickness in remote and polluted regions, Atmos. Chem. Phys., 9, 543-556.

Bennartz, R. (2007), Global assessment of marine boundary layer cloud droplet number concentration from satellite, J. Geophys. Res., 112, D02201, doi:10.1029/2006JD007547.

Bony, S., J.-L. Dufresne, T. H. Le, J.-J. Morcrette, and C. Senior (2004), On dynamic and thermodynamic components of cloud changes, Clim. Dyn., 22, 71-86, doi:10.1007/s00382-003-0369-6.

Brenguier, J.-L., H. Pawlowska, L. Schüller, R. Preusker, J. Fischer, and Y. Fouquart (2000), Radiative properties of boundary layer clouds: Droplet effective radius verses number concentration, J. Atmos. Sci., 57, 803-821.

Feingold, G., W. L. Eberhard, D. E. Veron, and M. Previdi (2003), First measurements of the Twomey indirect effect using ground-based remote sensors, Geophys. Res. Lett., 30(6), 1287, doi:10.1029/2002GL016633.

Forster, P., et al. (2007), Changes in atmospheric constituents and in radiative forcing, in Climate Change 2007: The Physical Science Basis. Contribution of Working Group I to the Fourth Assessment Report of the Intergovernmental Panel on Climate Change, edited by S. Solomon et al., chap. 2, pp. 129-234, Cambridge Univ. Press, Cambridge, U. K.

Grandey, B., and P. Stier (2010), A critical look at spatial scale choices in satellite-based aerosol indirect effect studies, Atmos. Chem. Phys., 10, 11,459-11,470, doi:10.5194/acp-10-11459-2010.

Gunn, R., and B. Phillips (1957), An experimental investigation of the effect of air pollution on the initiation of rain., J. Atmos. Sci., 14, $272-280$.

Huber, M., and R. Knutti (2011), Anthropogenic and natural warming inferred from changes in the earth's energy balance, Nat. Geosci., 5, 31-36, doi:10.1038/ngeo1327.

Jones, T. A., S. A. Christopher, and J. Quaas (2009), A six year satellitebased assessment of the regional variations in aerosol indirect effects, Atmos. Chem. Phys., 9, 4091-4114, doi:10.5194/acp-9-4091-2009. 
Kaufman, Y., I. Koren, L. Remer, D. Rosenfeld, and Y. Rudich (2005), The effect of smoke, dust, and pollution aerosol on shallow cloud development over the Atlantic Ocean, Proc. Natl. Acad. Sci. U. S. A., 102, 11,207-11,212, doi:10.1073/pnas.0505191102.

Kim, B.-G., S. Klein, and J. Norris (2005), Continental liquid water cloud variability and its parameterization using Atmospheric Radiation Measurement data, J. Geophys. Res., 110, D15S08, doi:10.1029/2004JD005122.

Koren, I., Y. Kaufman, D. Rosenfeld, L. Remer, and Y. Rudich (2005), Aerosol invigoration and restructuring of Atlantic convective clouds, Geophys. Res. Lett., 32, L14828, doi:10.1029/2005GL023187.

Platnick, S., M. King, S. Ackerman, W. Menzel, B. Baum, J. Riedi, and R. Frey (2003), The MODIS cloud products: Algorithms and examples from Terra, IEEE Trans. Geosci. Remote Sens., 41, 459-473, doi:10.1109/ TGRS.2002.808301.

Quaas, J., O. Boucher, and U. Lohmann (2006), Constraining the total aerosol indirect effect in the LMDZ and ECHAM4 GCMs using MODIS satellite data, Atmos. Chem. Phys., 6, 947-955, doi:10.5194/acp-6-947-2006.

Quaas, J., O. Boucher, N. Bellouin, and S. Kinne (2008), Satellite-based estimate of the direct and indirect aerosol climate forcing, J. Geophys. Res., 113, D05204, doi:10.1029/2007JD008962.

Quaas, J., et al. (2009), Aerosol indirect effects - general circulation model intercomparison and evaluation with satellite data, Atmos. Chem. Phys., 9, 8697-8717, doi:10.5194/acp-9-8697-2009.
Quaas, J., B. Stevens, P. Stier, and U. Lohmann (2010), Interpreting the cloud cover-Aerosol optical depth relationship found in satellite data using a general circulation model, Atmos. Chem. Phys., 10, 6129-6135, doi:10.5194/acp-10-6129-2010.

Remer, L., et al. (2005), The MODIS aerosol algorithm, products, and validation, J. Atmos. Sci., 62, 947-973, doi:10.1175/JAS3385.1.

Rossow, W. B., G. Tselioudis, A. Polak, and C. Jakob (2005), Tropical climate described as a distribution of weather states indicated by distinct mesoscale cloud property mixtures, Geophys. Res. Lett., 32, L21812, doi:10.1029/2005GL024584.

Stier, P., J. Seinfeld, S. Kinne, and O. Boucher (2007), Aerosol absorption and radiative forcing, Atmos. Chem. Phys., 7, 5237-5261, doi:10.5194/ acp-7-5237-2007.

Twomey, S. (1977), The influence of pollution on the shortwave albedo of clouds., J. Atmos. Sci., 34, 1149-1152.

Williams, K., and M. Webb (2009), A quantitative performance assessment of cloud regimes in climate models, Clim. Dyn., 33, 141-157, doi:10.1007/s00382-008-0443-1.

Yuan, T., Z. Li, R. Zhang, and J. Fan (2008), Increase of cloud droplet size with aerosol optical depth: An observation and modeling study, J. Geophys. Res., 113, D04201, doi:10.1029/2007JD008632.

Zuidema, P., E. Westwater, C. Fairall, and D. Hazen (2005), Ship-based liquid water path estimates in marine stratocumulus, J. Geophys. Res. 110, D20206, doi:10.1029/2005JD005833. 